\title{
SCREENING SELECTION OF ENHANCED OIL RECOVERY METHODS BASED ON ANALYTICS OF WORLDWIDE OILFIELD DATA WITH REFERENCE TO OFFSHORE OIL FIELDS IN VIETNAM
}

\author{
Doan Huy Hien, Hoang Long, Pham Quy Ngoc \\ Vietnam Petroleum Institute \\ Email: hiendh@vpi.pvn.vn \\ https://doi.org/10.47800/PVJ.2021.06-01
}

\section{Summary}

Selecting a proper enhanced oil recovery (EOR) method for a prospective reservoir is a key factor for successful application of EOR techniques. Reservoir engineers usually refer to screening guidelines to identify potential EOR processes for a given reservoir. However, these guidelines are often too general. In this study, we develop an advanced EOR screening technique based on the statistical analyses with boxplot in combination with some initial deep learning analyses to select the most suitable EOR method for a given mature oil field. At first, a database and the screening guidelines were established by compiling the information of 1,098 EOR projects from various publications in different languages, including Oil and Gas Journal (OGJ) biannual EOR surveys, SPE publications, DOE reports, and Chinese publications, etc. Boxplots were used to detect the special cases for each reservoir/fluid property and to present the graphical screening results. A case study was used to demonstrate that with a simple input of reservoir/fluid information, the proposed procedure could effectively give recommendations for EOR method selection. With the inputs (reservoir and fluid properties) from Vietnam offshore oil fields, the EOR methods recommended by this study are mostly chemical, including polymer and surfactant injection.

Key words: Enhanced oil recovery (EOR), database, statistical analyses, deep learning.

\section{Introduction}

The life of an oil and gas reservoir goes through different production stages, namely primary, secondary, and tertiary recovery. Primary recovery is carried out by naturally initial reservoir drive energy such as rock and fluid expansion, solution gas, water influx, gas cap or gravity drainage. Secondary recovery requires the injection of external fluid (water or gas) mainly for the purpose of pressure maintenance and volumetric sweep efficiency. The tertiary stage refers to recovery by injection of more special fluids such as chemical, miscible gases or thermal energy after the secondary.

EOR is an essential technique for extending the lifetime of reservoirs, especially for mature oil fields where productivity has declined or the reservoir pressure rapidly reduces. EOR may include physical, mechanical and chemical processes, such as infill drilling, waterflooding,

Date of receipt: 27/10/2020. Date of review and editing: 27/10/2020 - 18/3/2021. Date of approval: 11/6/2021. gas and/or chemical injection. There are more than 20 EOR techniques which are classified as thermal (steam flooding, in-situ combustion) and nonthermal methods including chemical (polymer, surfactant, polymer/ surfactant) and miscible (hydrocarbon gas, $\mathrm{CO}_{2}$, and nitrogen injection) [1].

Generally, by applying various EOR technologies to different oil fields, crude oil production from a reservoir could be increased up to $30 \%$. Therefore, EOR technologies are important in the oil industry and have been used worldwide [2]. The main mechanism of EOR is to inject into the reservoir an agent to improve the oil displacement efficiency by modifying the reservoir rock and fluid properties such as interfacial tension, capillary pressure, viscosity, density, and mobility ratio. EOR selection is a complex process depending on reservoir characterisation, technology availability and economical confirmation to find the most appropriate method for further reservoir simulation, economic evaluation and field planning. In 1978, the first EOR screening studies were presented by Brashear and Kuuskraa [3], using 
200 pilot projects in the USA. After that, especially since the late 1990s, EOR screening criteria for broader EOR processes have been discussed by more researchers, and more methodologies have been developed. By far, EOR screening could be classified as conventional and advanced methods.

The conventional EOR screening is based on statistical methods, which generally use ranges or intervals of reservoir/fluid properties to filter out the applicable EOR technologies. Look-up tables coming from the statistical analysis of the existing EOR projects are provided with different property intervals for each EOR method. One well-known EOR screening guideline was proposed by Taber et al. in 1997 [4], which provides screening criteria (known as Taber's tables) based on the EOR projects conducted from 1974 to $1996[4,5]$. The screening method used six important parameters that were considered in suitable ranges, including oil gravity, oil viscosity, oil saturation, average permeability, depth, and temperature. Similarly, Al-Adasani and Bai updated the Taber's screening guidelines by adding data from 1998 to 2010 [6]. Miscible and immiscible flooding were distinguished for all gas injection technologies, and the porosity guidelines were newly added in their work [6]. Even though both Taber and Al-Adasani provide useful guidelines for each EOR technique, updating screening guidelines along with the dramatic increase of EOR projects is crucial since the conventional screening guidelines were constructed based on existing projects and experts' knowledge. Therefore, it is necessary to update the screening guidelines with projects conducted since 2010.

The advanced EOR screening method uses modern Al algorithms to process the available EOR project data for EOR selection based on similarity. The similarity here is understood as either physical distance (Euclidian, Manhattan, Jaccard, etc.) or probability distance. The application of Al algorithms in EOR selection is promising because it is capable of recommending a proper selection for EOR method by capturing the small patterns in the implementation of EOR techniques, revealing the relationships among the reservoir/fluids properties and predicting the physical properties for EOR. Alvarado et al. [7] proposed a methodology by utilising the machine learning algorithm (the combination of different clustering algorithms and expert systems) to draw the rules for EOR screening. Six clusters were classified based on the dataset, and each cluster has its own rules for application. Siena et al. [8] developed a methodology for target reservoirs analogy by applying the Bayesian hierarchical clustering algorithm.

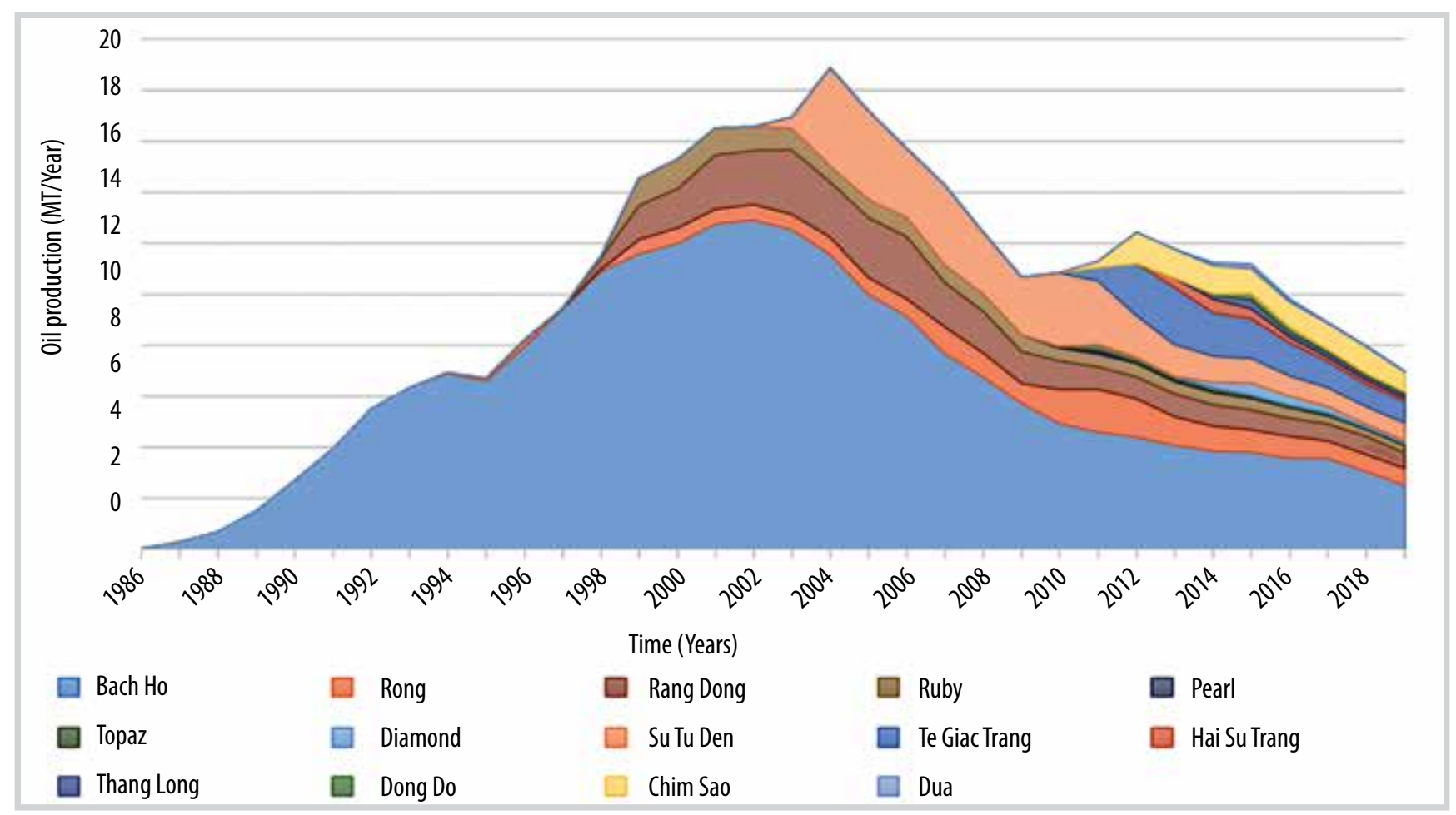

Figure 1. Production curve of many oil fields showing the declining period. 
Partition Zone of Norway and Scotlan

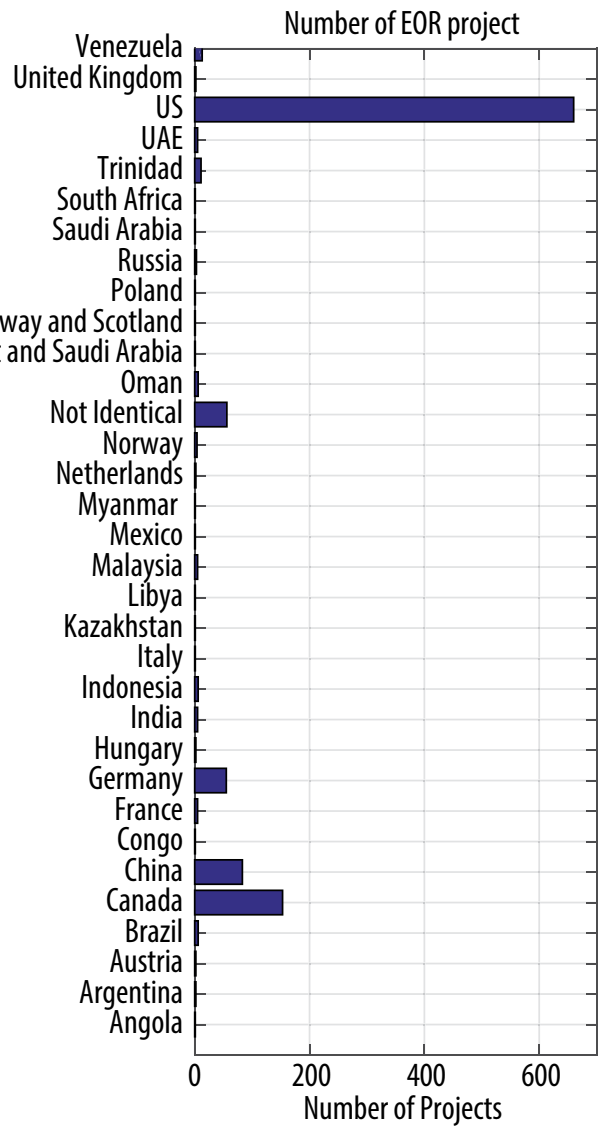

Figure 2. Number of EOR projects of each countries.

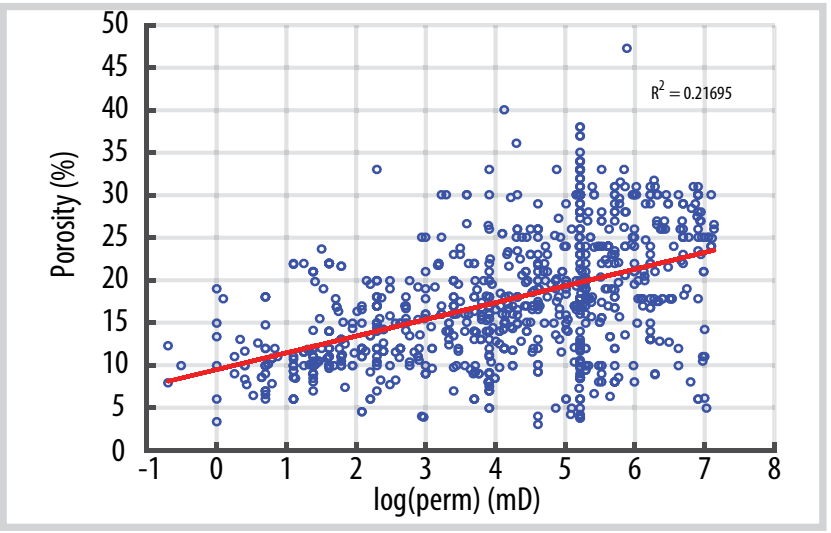

(a)

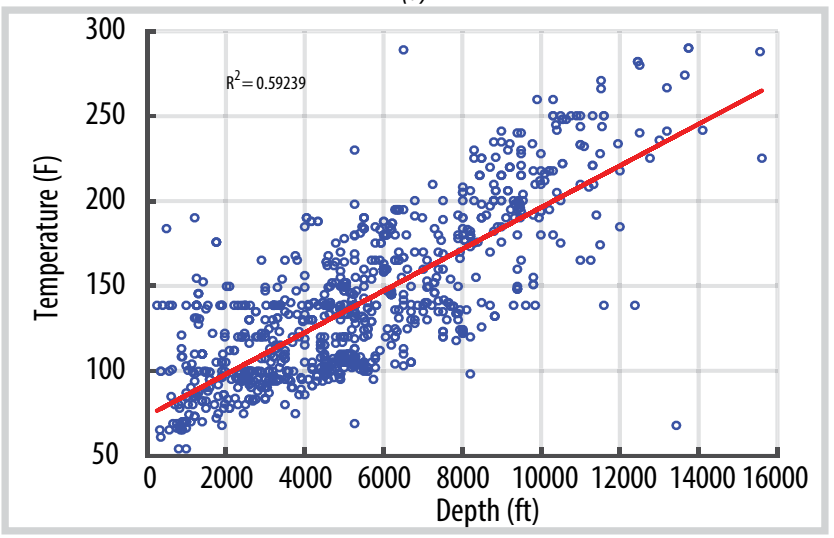

(c)

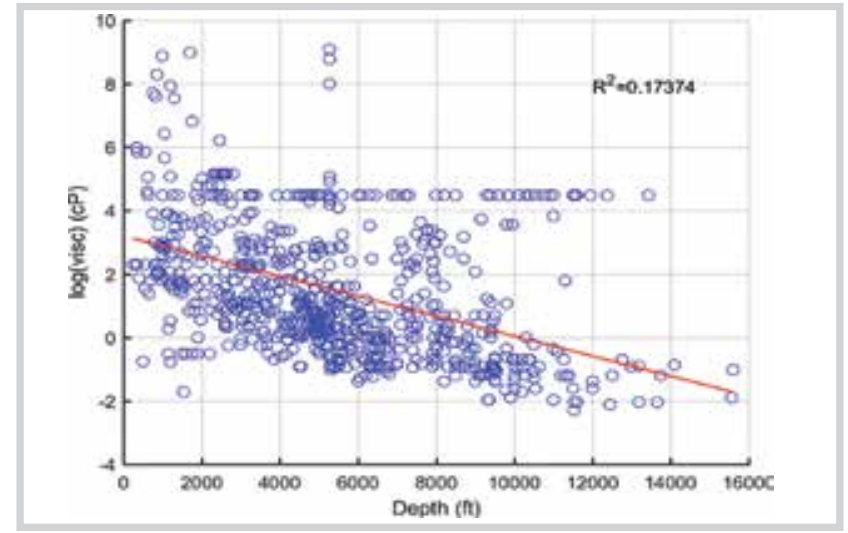

(b)

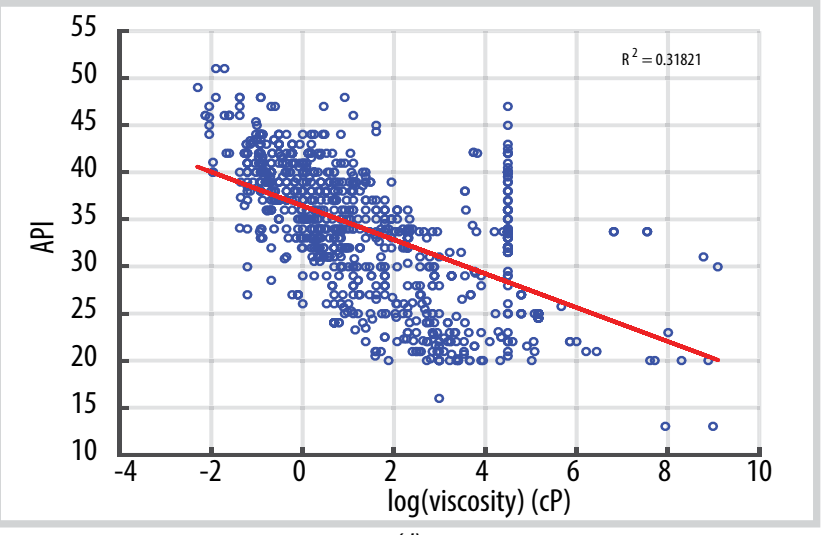

(d)

Figure 3. Relationship of oil fields parameters: a) Porosity and permeability; b) Depth and viscosity; c) Depth and temperature and d) API and viscosity. 
of EOR projects all over the world; ii) statistically analyse the collected data; and iii) develop the statistical and machine learning approaches to get the most suitable EOR method for the offshore Vietnam oil field.

\section{Data preparation and preprocessing}

For EOR screening, it is required to get as much as possible information of the EOR projects worldwide to create an EOR database for later analyses. Establishing an EOR database is a great challenge because data are scattered and reported in a variety of documentation forms and languages. In this research, the EOR data were collected from the most updated EOR projects published biyearly by the Oil and Gas Journal, in a similar format used by many other researchers such as $[2,15$ - 19]. This dataset is summarised in table style and collected from 33 countries, mainly from USA and Canada (more than 840 projects, equivalent to $76 \%$ ) as seen in Figure 2. In fact, many countries have only one EOR project published. The dataset covering porosity, permeability, initial water saturation, reservoir depth, reservoir area, oil viscosity, and temperature will be used as an input for analyses and interpretation.

Pre-processing the collected data is necessary as the data of many EOR projects is missing or reported in a range of values, e.g. the porosity can be reported as a range of $10-22 \%$ instead of an exact value. For this kind of data, the average value will be calculated and used. Similarly, the missing data will be interpolated by linear correlation between two close parameters such as porosity and logarithm of permeability, viscosity and specific gravity (API), temperature and depth, or depth and viscosity. These linear correlations are shown in Figures 3a-d respectively, which will be used as a function to

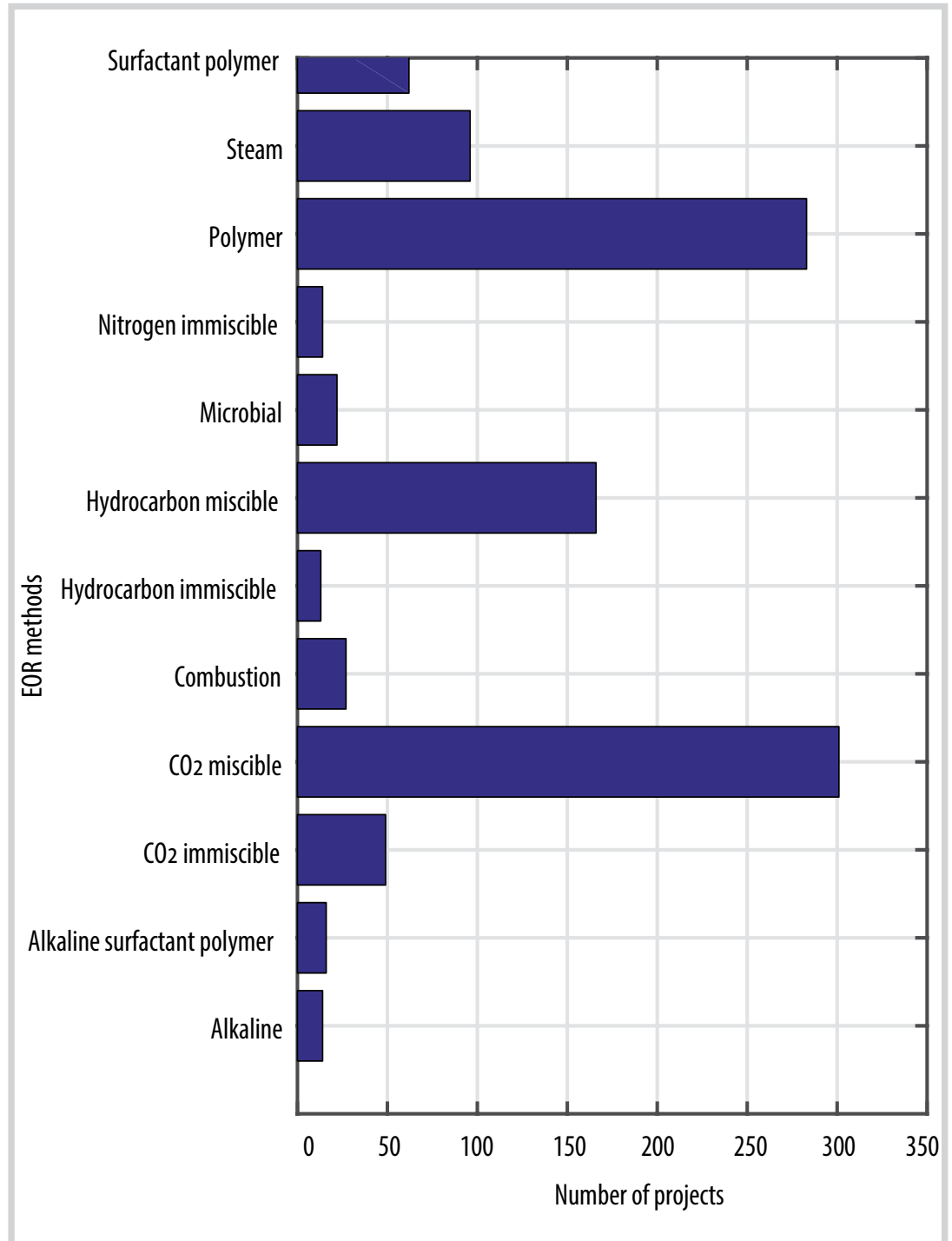

Figure 4. Number of EOR projects used for data analyses.

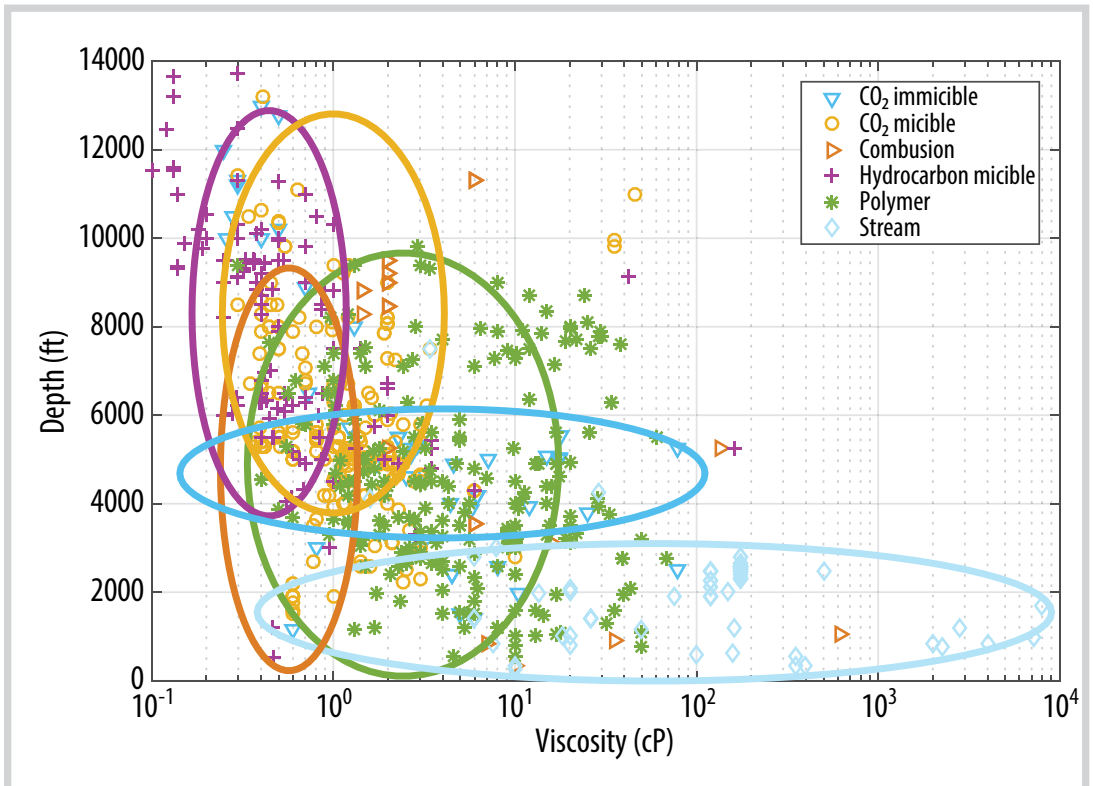

Figure 5. Modified conventional screening guidelines by Taber et al. [4, 5]. 


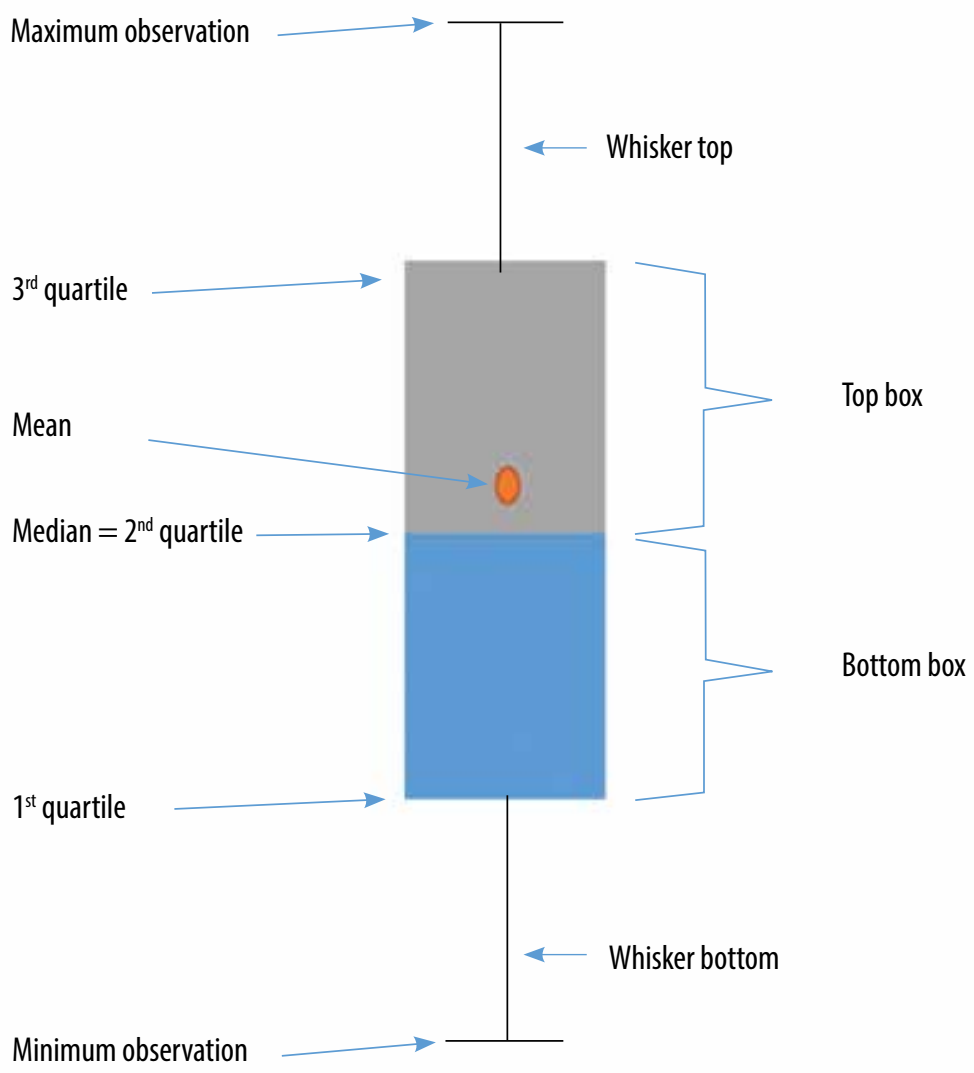

Figure 6. Schematic of boxplot.

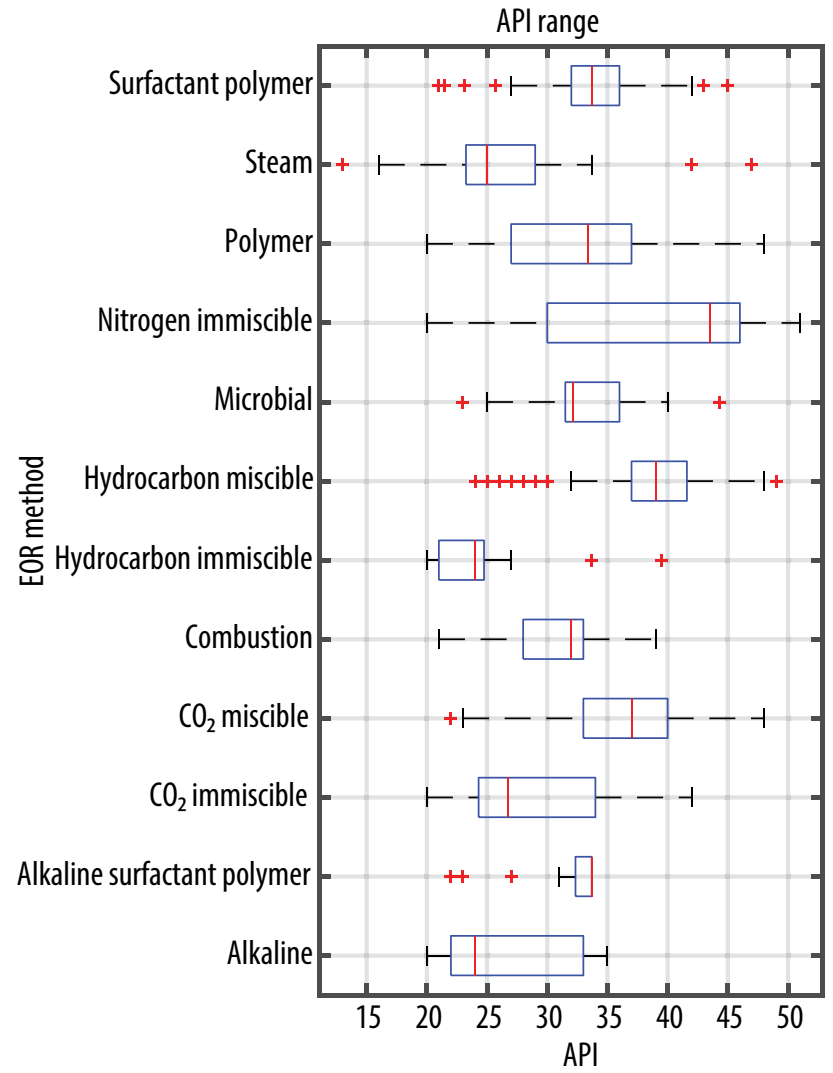

(a) recover and fill up the missing data. For some parameters that do not have any relationship or very loose relationship with the other parameters such as initial oil saturation and area, the filling up method will be the mean values of these available data. For the few data that are out of physical ranges or linear range, they are also corrected. Additionally, the oils produced offshore Vietnam are light oils with API from 30 to 40 and viscosity from 0.8 to $4 \mathrm{cP}$. Thus, the thermal EOR method will not be appropriate as it is more suitable for heavy and high viscosity oils. It is worth noting that the data filter needs to be applied for the collected data to make them more diverse, compared to other papers such as the one by Zhang [2]. In this particular data set, we filter out all the data with viscosity higher than $10,000 \mathrm{cP}$. The number of EOR projects is shown in Figure 4, where the majority are $\mathrm{CO}_{2}$ miscible projects while the rest are other thermal projects such as steam or combustion.

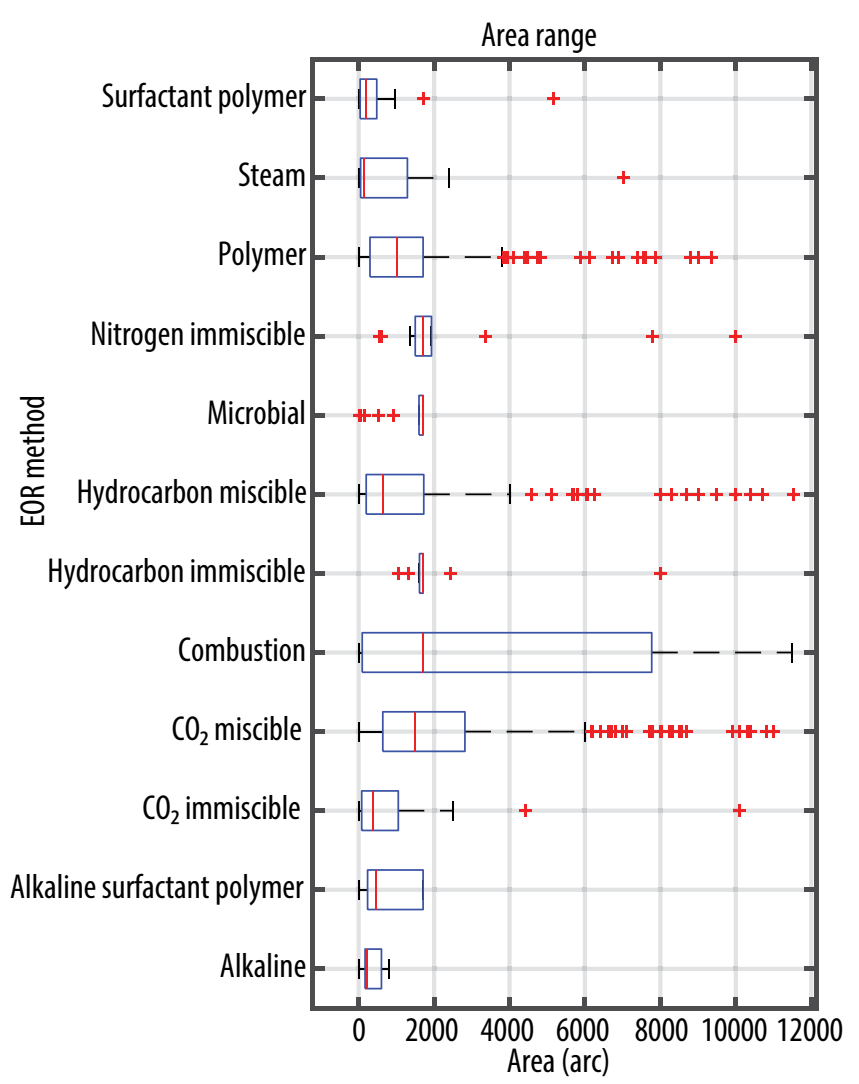




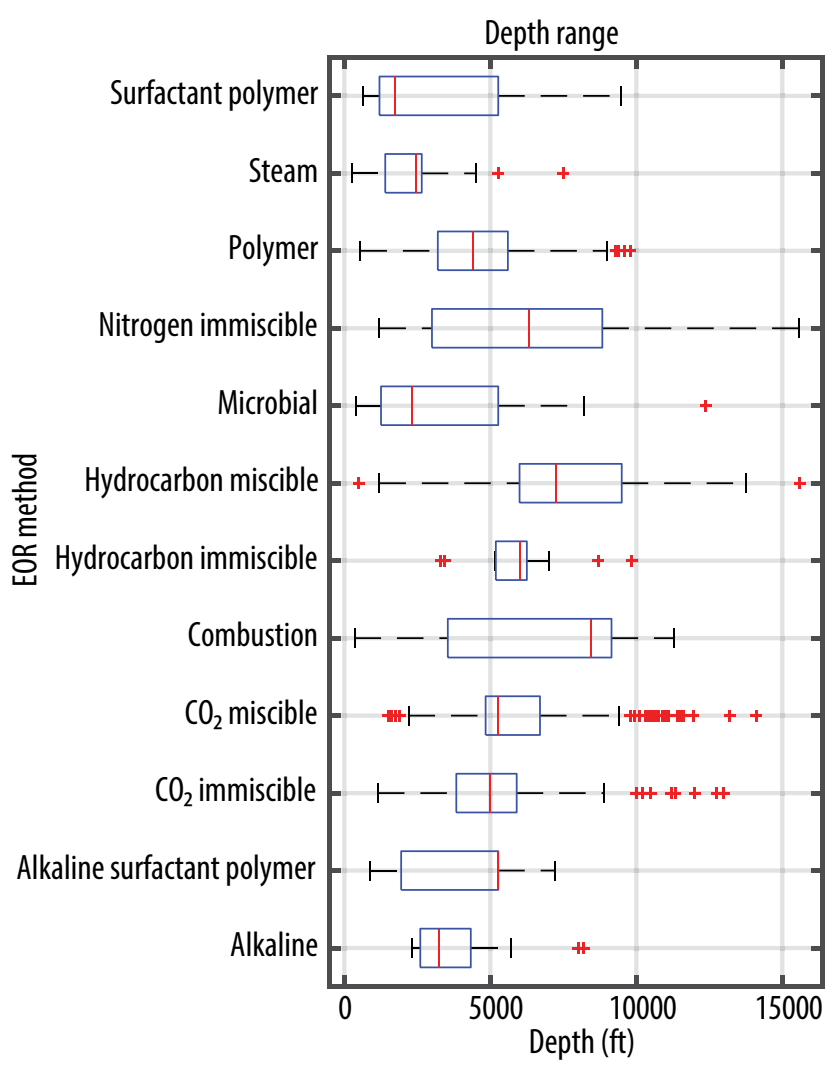

(c)

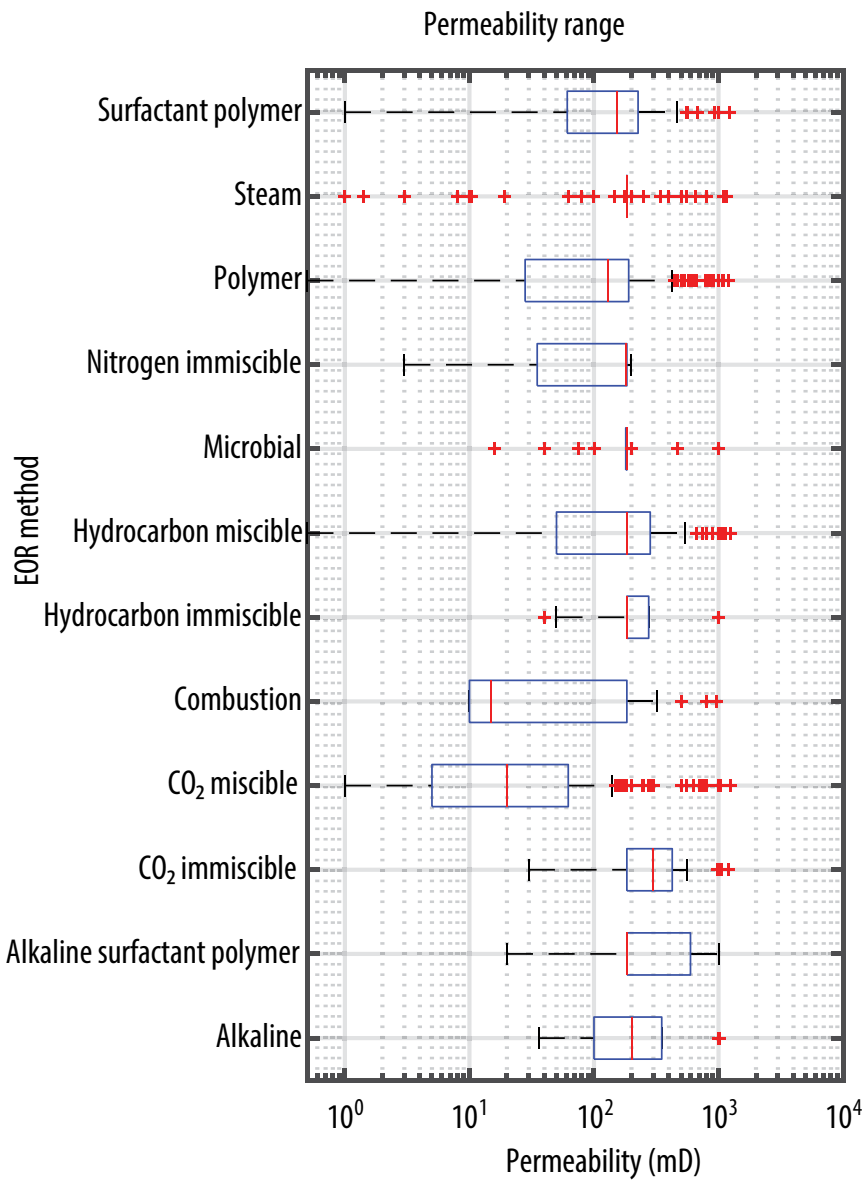

(e)

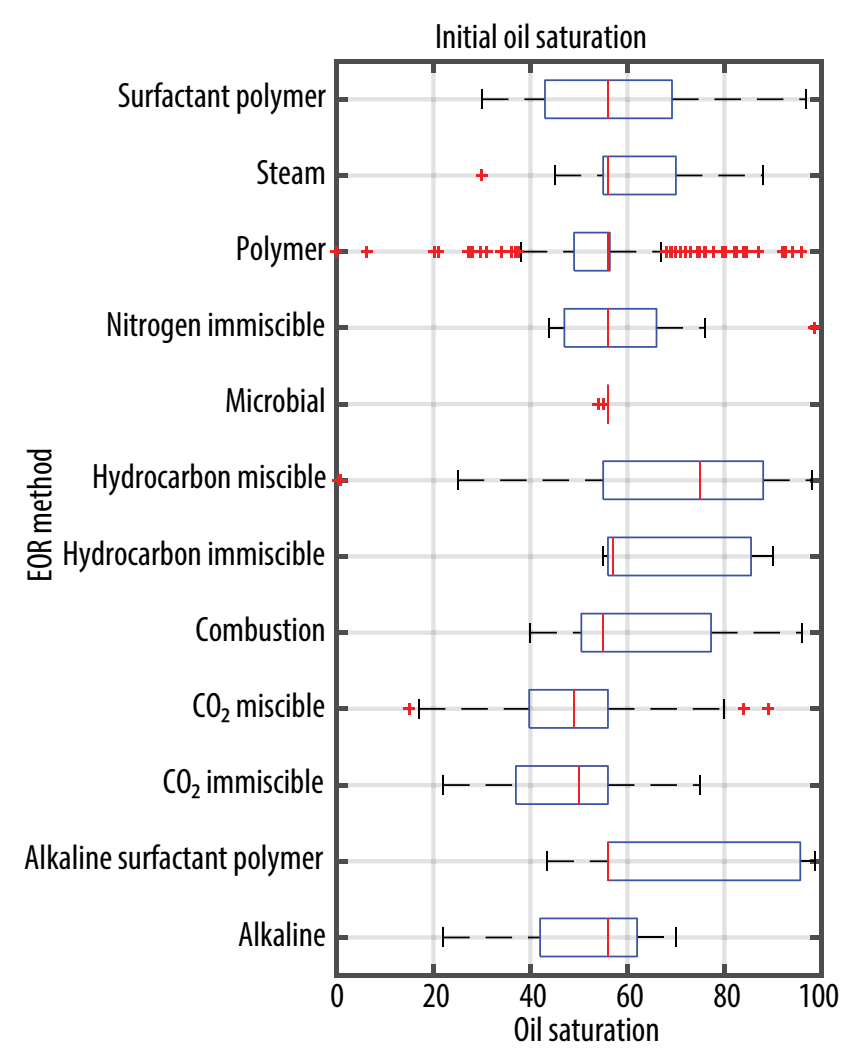

(d)

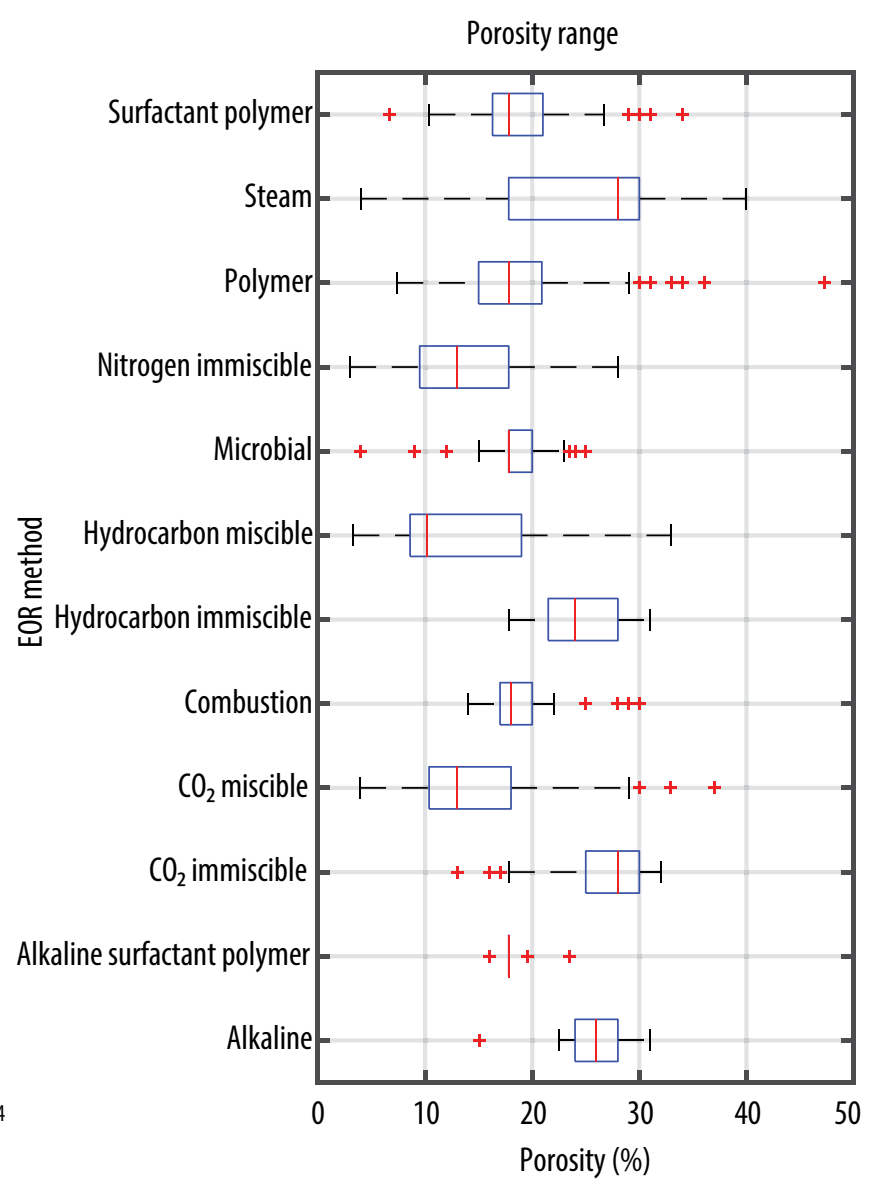

(f) 

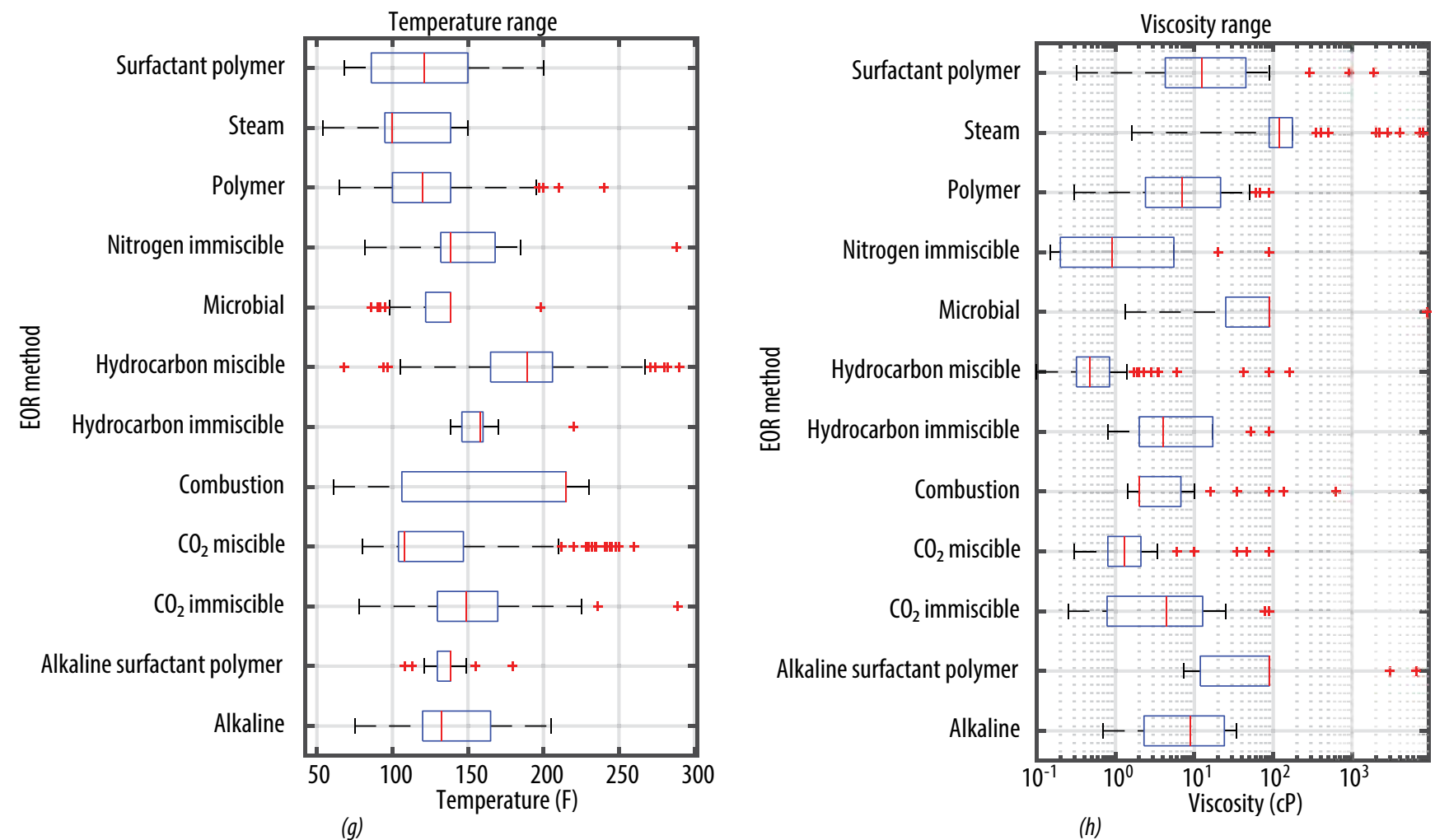

Figure 7. Boxplot analyses of reservoir and fluid properties of EOR projects.

Table 1. Statistical summarisation of porosity (\%) from collected EOR projects

\begin{tabular}{|l|r|r|r|r|r|}
\hline \multicolumn{1}{|c|}{ EOR method } & Min. & Max. & q25 & Mean & \multicolumn{1}{c|}{ q75 } \\
\hline Alkaline & 15.10 & 31.00 & 24.00 & 26.00 & 28.00 \\
\hline Alkaline surfactant polymer & 16.00 & 23.50 & 17.81 & 17.81 & 17.81 \\
\hline $\mathrm{CO}_{2}$ immiscible & 13.00 & 32.00 & 25.00 & 28.00 & 30.00 \\
\hline $\mathrm{CO}_{2}$ miscible & 3.93 & 37.00 & 10.00 & 12.00 & 18.00 \\
\hline Combustion & 14.00 & 29.00 & 17.00 & 18.00 & 20.00 \\
\hline Hydrocarbon immiscible & 20.00 & 31.00 & 22.00 & 24.00 & 28.00 \\
\hline Hydrocarbon miscible & 4.25 & 33.00 & 8.60 & 10.15 & 20.00 \\
\hline Microbial & 12.00 & 24.00 & 17.20 & 19.00 & 20.00 \\
\hline Nitrogen immiscible & 3.00 & 28.00 & 6.65 & 11.95 & 16.50 \\
\hline Polymer & 7.40 & 47.30 & 14.38 & 17.45 & 21.53 \\
\hline Steam & 4.00 & 40.00 & 24.75 & 30.00 & 30.00 \\
\hline Surfactant polymer & 10.40 & 34.00 & 15.70 & 19.00 & 21.60 \\
\hline
\end{tabular}

Table 2. Statistical summarisation of permeability ( $\mathrm{mD}$ ) from collected EOR projects

\begin{tabular}{|l|r|r|r|r|r|}
\hline \multicolumn{1}{|c|}{ EOR method } & Min. & Max. & \multicolumn{1}{c|}{ q25 } & \multicolumn{1}{c|}{ Mean } & \multicolumn{1}{c|}{ q75 } \\
\hline Alkaline & 36.00 & 1025.00 & 100.00 & 201.84 & 350.00 \\
\hline Alkaline surfactant polymer & 60.00 & 1000.00 & 501.00 & 601.50 & 676.00 \\
\hline $\mathrm{CO}_{2}$ immiscible & 30.00 & 1200.00 & 179.34 & 275.00 & 450.00 \\
\hline $\mathrm{CO}_{2}$ miscible & 1.00 & 1255.00 & 4.01 & 11.00 & 50.05 \\
\hline Combustion & 10.00 & 958.00 & 10.00 & 10.00 & 147.17 \\
\hline Hydrocarbon immiscible & 40.00 & 1000.00 & 183.68 & 183.68 & 275.00 \\
\hline Hydrocarbon miscible & 0.50 & 1250.00 & 50.00 & 183.68 & 300.00 \\
\hline Microbial & 16.00 & 465.00 & 120.38 & 183.68 & 200.00 \\
\hline Nitrogen immiscible & 3.00 & 200.00 & 19.75 & 137.50 & 183.68 \\
\hline Polymer & 0.50 & 1200.00 & 22.75 & 95.30 & 200.00 \\
\hline Steam & 1.00 & 1150.00 & 168.00 & 183.68 & 183.68 \\
\hline Surfactant polymer & 1.00 & 1218.00 & 50.00 & 115.00 & 197.00 \\
\hline
\end{tabular}


Table 3. Statistical summarisation of depth (ft) from collected EOR projects

\begin{tabular}{|c|c|c|c|c|c|}
\hline EOR method & Min. & Max. & q25 & Mean & q75 \\
\hline Alkaline & 2300.00 & 8200.00 & 2600.00 & 3250.00 & 4330.00 \\
\hline Alkaline surfactant polymer & 870.00 & 5300.00 & 875.00 & 886.50 & 5279.45 \\
\hline $\mathrm{CO}_{2}$ immiscible & 1400.00 & 13000.00 & 3975.00 & 5279.45 & 7254.25 \\
\hline $\mathrm{CO}_{2}$ miscible & 1900.00 & 14100.00 & 4900.00 & 5279.45 & 6000.00 \\
\hline Combustion & 347.50 & 11300.00 & 3550.00 & 8450.00 & 9050.00 \\
\hline Hydrocarbon immiscible & 3300.00 & 8700.00 & 5162.50 & 6000.00 & 6000.00 \\
\hline Hydrocarbon miscible & 500.00 & 15600.00 & 6000.00 & 6750.00 & 9432.00 \\
\hline Microbial & 400.00 & 5740.00 & 1390.13 & 1970.00 & 4534.59 \\
\hline Nitrogen immiscible & 1200.00 & 15565.00 & 4939.72 & 8092.50 & 10167.50 \\
\hline Polymer & 550.00 & 9800.00 & 3000.00 & 4400.00 & 5802.25 \\
\hline Steam & 250.00 & 7500.00 & 1400.00 & 2350.00 & 2600.00 \\
\hline Surfactant polymer & 650.00 & 9460.00 & 1074.00 & 1900.00 & 5279.45 \\
\hline
\end{tabular}

Table 4. Statistical summarisation of area (arc) from collected EOR projects

\begin{tabular}{|l|r|r|r|r|r|}
\hline \multicolumn{1}{|c|}{ EOR method } & Min. & Max. & q25 & \multicolumn{1}{c|}{ Mean } & q75 \\
\hline Alkaline & 1.00 & 800.00 & 170.00 & 228.50 & 604.00 \\
\hline Alkaline surfactant polymer & 1.00 & 1708.63 & 236.44 & 450.78 & 1708.63 \\
\hline $\mathrm{CO}_{2}$ immiscible & 5.00 & 10104.00 & 81.00 & 380.00 & 1050.75 \\
\hline $\mathrm{CO}_{2}$ miscible & 5.00 & 11000.00 & 640.00 & 1500.00 & 2817.50 \\
\hline Combustion & 6.00 & 11500.00 & 94.25 & 1708.63 & 7770.00 \\
\hline Hydrocarbon immiscible & 1052.00 & 8000.00 & 1612.72 & 1708.63 & 1708.63 \\
\hline Hydrocarbon miscible & 12.20 & 11520.00 & 200.00 & 640.00 & 1726.00 \\
\hline Microbial & 10.00 & 1708.63 & 1600.00 & 1708.63 & 1708.63 \\
\hline Nitrogen immiscible & 540.00 & 10000.00 & 1500.00 & 1708.63 & 1931.00 \\
\hline Polymer & 2.50 & 9360.00 & 300.00 & 1024.00 & 1708.63 \\
\hline Steam & 9.00 & 7020.00 & 51.50 & 133.50 & 1292.50 \\
\hline Surfactant polymer & 1.00 & 5161.00 & 40.00 & 199.50 & 480.00 \\
\hline
\end{tabular}

Table 5. Statistical summarisation of oil saturation (\%) from collected EOR projects

\begin{tabular}{|l|r|r|r|r|r|}
\hline \multicolumn{1}{|c|}{ EOR method } & Min. & Max. & q25 & Mean & \multicolumn{1}{c|}{ q75 } \\
\hline Alkaline & 22.00 & 70.00 & 42.00 & 55.99 & 62.00 \\
\hline Alkaline surfactant polymer & 43.50 & 98.70 & 55.99 & 55.99 & 95.65 \\
\hline $\mathrm{CO}_{2}$ immiscible & 22.00 & 75.00 & 37.00 & 50.00 & 55.99 \\
\hline $\mathrm{CO}_{2}$ miscible & 15.00 & 89.00 & 39.75 & 49.00 & 55.99 \\
\hline Combustion & 40.00 & 96.00 & 50.50 & 55.00 & 77.25 \\
\hline Hydrocarbon immiscible & 55.00 & 90.00 & 55.99 & 57.00 & 85.50 \\
\hline Hydrocarbon miscible & 0.40 & 98.00 & 55.00 & 75.00 & 88.00 \\
\hline Microbial & 54.00 & 55.99 & 55.99 & 55.99 & 55.99 \\
\hline Nitrogen immiscible & 43.80 & 98.50 & 47.00 & 55.99 & 66.00 \\
\hline Polymer & 0.00 & 95.90 & 49.00 & 55.99 & 56.38 \\
\hline Steam & 30.00 & 88.00 & 55.00 & 55.99 & 70.00 \\
\hline Surfactant polymer & 30.00 & 96.90 & 43.00 & 55.99 & 69.20 \\
\hline
\end{tabular}

\section{Conventional EOR screening method}

Following the method presented in Zhang et al., [2], Figure 5 illustrates a modified graphical screening guideline that was created by Taber et al. [4, 5] for depth and viscosity. Regions enclosed within the ellipses represent the applicable ranges for each EOR technique.
Here we can see that the thermal method can only be applied for the shallow reservoirs with a very high range of viscosity, while the viscosity for application of polymer EOR is less than $100 \mathrm{cP}$. Similarly, the gas injection method (hydrocarbon and $\mathrm{CO}_{2}$ miscible) should be applied for deep reservoirs with low viscosity (less than $3 \mathrm{CP}$ ). 
Table 6. Statistical summarisation of oil viscosity (CP) from collected EOR projects

\begin{tabular}{|c|c|c|c|c|c|}
\hline EOR method & Min. & Max. & q25 & Mean & q75 \\
\hline Alkaline & 0.70 & 34.00 & 2.30 & 8.85 & 24.00 \\
\hline Alkaline surfactant polymer & 7.40 & 15.60 & 8.20 & 9.25 & 13.50 \\
\hline $\mathrm{CO}_{2}$ immiscible & 0.25 & 78.00 & 0.72 & 2.95 & 6.70 \\
\hline $\mathrm{CO}_{2}$ miscible & 0.30 & 46.00 & 0.70 & 1.20 & 1.80 \\
\hline Combustion & 1.44 & 136.00 & 2.00 & 2.00 & 6.00 \\
\hline Hydrocarbon immiscible & 0.80 & 52.00 & 2.00 & 2.20 & 4.90 \\
\hline Hydrocarbon miscible & 0.10 & 160.00 & 0.32 & 0.46 & 0.83 \\
\hline Microbial & 1.32 & 28.00 & 3.43 & 6.50 & 22.50 \\
\hline Nitrogen immiscible & 0.15 & 20.00 & 0.20 & 0.60 & 4.35 \\
\hline Polymer & 0.30 & 68.00 & 1.88 & 4.80 & 13.00 \\
\hline Steam & 1.60 & 400.00 & 26.00 & 150.00 & 175.00 \\
\hline Surfactant polymer & 0.32 & 288.00 & 3.25 & 7.00 & 18.00 \\
\hline
\end{tabular}

Table 7. Statistical summarisation of oil temperature (F) from collected EOR projects

\begin{tabular}{|l|r|r|r|r|r|}
\hline \multicolumn{1}{|c|}{ EOR method } & Min. & Max. & q25 & Mean & q75 \\
\hline Alkaline & 75.00 & 205.00 & 120.00 & 132.50 & 165.00 \\
\hline Alkaline surfactant polymer & 108.14 & 155.00 & 108.32 & 116.96 & 149.00 \\
\hline $\mathrm{CO}_{2}$ immiscible & 78.00 & 289.00 & 124.50 & 148.00 & 184.50 \\
\hline $\mathrm{CO}_{2}$ miscible & 80.00 & 250.00 & 104.00 & 106.00 & 140.00 \\
\hline Combustion & 61.00 & 230.00 & 118.75 & 215.00 & 216.25 \\
\hline Hydrocarbon immiscible & 146.00 & 220.00 & 150.25 & 158.00 & 160.00 \\
\hline Hydrocarbon miscible & 94.00 & 290.00 & 165.00 & 189.00 & 206.00 \\
\hline Microbial & 86.00 & 138.55 & 90.50 & 95.00 & 116.00 \\
\hline Nitrogen immiscible & 82.00 & 288.00 & 131.00 & 135.27 & 171.00 \\
\hline Polymer & 65.00 & 240.00 & 95.00 & 115.00 & 136.00 \\
\hline Steam & 54.00 & 150.00 & 95.00 & 100.00 & 110.00 \\
\hline Surfactant polymer & 68.00 & 200.00 & 74.00 & 104.00 & 133.70 \\
\hline
\end{tabular}

Table 8. Statistical summarisation of API from collected EOR projects

\begin{tabular}{|c|c|c|c|c|c|}
\hline EOR method & Min. & Max. & $\mathbf{q 2 5}$ & Mean & q75 \\
\hline Alkaline & 20.00 & 35.00 & 22.00 & 24.00 & 33.00 \\
\hline Alkaline surfactant polymer & 22.00 & 33.69 & 27.00 & 33.69 & 33.69 \\
\hline $\mathrm{CO}_{2}$ immiscible & 20.00 & 42.00 & 25.00 & 27.85 & 33.85 \\
\hline $\mathrm{CO}_{2}$ miscible & 23.00 & 48.00 & 33.00 & 36.50 & 40.00 \\
\hline Combustion & 21.50 & 39.00 & 28.00 & 33.00 & 33.00 \\
\hline Hydrocarbon immiscible & 20.00 & 27.00 & 21.00 & 24.00 & 24.00 \\
\hline Hydrocarbon miscible & 24.00 & 49.00 & 37.00 & 39.00 & 41.60 \\
\hline Microbial & 23.00 & 44.30 & 31.80 & 33.00 & 38.50 \\
\hline Nitrogen immiscible & 20.00 & 51.00 & 29.00 & 44.00 & 46.00 \\
\hline Polymer & 20.00 & 48.00 & 26.08 & 33.00 & 38.00 \\
\hline Steam & 16.00 & 47.00 & 24.50 & 25.00 & 26.25 \\
\hline Surfactant polymer & 21.00 & 45.00 & 30.25 & 33.69 & 36.00 \\
\hline
\end{tabular}

To provide an easy, straightforward, and comprehensive screening guideline, a boxplot matrix is created to visualise all the ranges for reservoir/fluid properties. A boxplot is shown in Figure 6, which reveals the minimum, $25^{\text {th }}$ percentile (Q1), median, $75^{\text {th }}$ percentile (Q3), and the maximum. The lower and upper limits are normally within the minimum and maximum values. In statistics, when the value is smaller than the lower limit or greater than the upper limit, it will be considered as outliers. However, for the construction of screening guidelines, the detected outliers are regarded as special cases after data cleansing that could not be ignored 
because each case represents either an extreme reservoir/fluid situation or a new development for the implementation of an EOR technique. With the given data collected, 8 primary parameters, namely API, depth, area, porosity, permeability, oil saturation, temperature, and viscosity, are considered the background for the EOR guideline as shown in Figure 7. These boxplots illustrate the distribution of the above-mentioned parameters for the successful EOR projects that were used to obtain the required statistics involving the minimum, maximum, average, $1^{\text {st }}$ quartile, $2^{\text {nd }}$ quartile (median) and $3^{\text {rd }}$ quartile for each variable. These parameters were determined from the successful EOR data set and then defined the intervals for the data distribution in horizontal axis. These statistical parameters for each EOR method are summarised in Tables $1-8$, based on which we can make the scoring and rating for a given oil field. For example, considering surfactant as an EOR technique, the lower and upper limits of the variable saturation for successful projects (Figure $7 \mathrm{~d}$ ) are 30 and $96.9 \%$ and for a given range of Vietnam's oil fields are 40 and $80 \%$ (Table 9); [30 - 96.9] $\cap[40$ - 80] $=[40-80]$, which means the values within the range of (Figure 7) 40 and 80\% of initial water saturation may be suitable for surfactant polymer injection method. Following the outcome of the boxplots and other similar plots such as scatter plots (Figure 3), the histogram technique can be used to represent the distribution of the data sets. As seen in Figure 3, the correlation coefficients are relatively small because most of the data collected here come from different fields and sites all over the world instead of one certain location.

\section{Advanced EOR screening guideline by deep learning approach}

Recent development of deep learning algorithms has been applied in many fields of the petroleum industry from exploration
Table 9. Common activation functions used in deep learning and ANN

\begin{tabular}{|c|c|c|}
\hline Activation function & Plot & Equation \\
\hline Sigmoid & & $f(x)=\sigma(x)=\frac{1}{1+e^{-x}}$ \\
\hline Tanh & & $f(x)=\tanh (x)=\frac{e^{x}-e^{-x}}{e^{x}+e^{-x}}$ \\
\hline ReLU & & $f(x)= \begin{cases}0, & x<0 \\
x, & x \geq 0\end{cases}$ \\
\hline Leaky ReLU & & $f(x)= \begin{cases}\epsilon x, & x<0 \\
x, & x \geq 0\end{cases}$ \\
\hline ELU & & $f(x)=\left\{\begin{array}{l}\alpha\left(e^{x}-1\right), \quad x<0 \\
x, \quad x \geq 0\end{array}\right.$ \\
\hline Identity & & $f(x)=x$ \\
\hline
\end{tabular}

\begin{tabular}{|c|c|c|c|}
\hline $\begin{array}{l}\text { Input } \\
\text { layer }\end{array}$ & $\begin{array}{l}\text { Hidden } \\
\text { layer } 1\end{array}$ & $\begin{array}{l}\text { Hidden } \\
\text { layer } 2\end{array}$ & $\begin{array}{l}\text { Hidden } \\
\text { layer } 3\end{array}$ \\
\hline
\end{tabular}

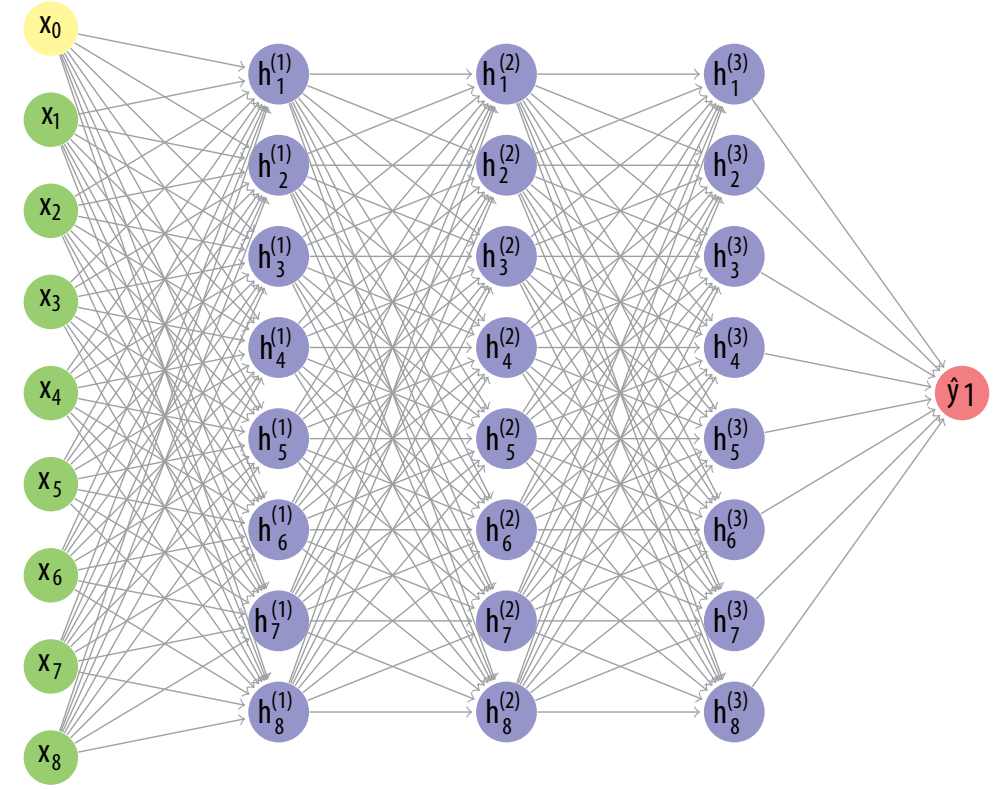

Figure 8. A deep learning network designed for this EOR screening problem, the input layer ( $x 1$ to $x 8$ ) is made of 8 reservoir properties and the output layer will be an EOR method. 
to production. The principle of deep learning is based on the artificial neuron network (ANN) approach in which the number of hidden layers is more than one while the ANN consists of only one hidden layer [20] as shown in Figure 8. In this problem for EOR selection, the deep learning network consists of an 8-input layer, 3 hidden layers with 8 neurons each and 1 output layer. However, the number of hidden layers as well as the number of neurons in each hidden layer are not optimised as it is beyond the scope of this research. The input layer consists of 8 reservoir properties (area, depth, porosity, permeability, and temperature) and fluid properties (viscosity and density ( $\left.{ }^{\circ} \mathrm{API}\right)$ ), initial oil saturation denoted as $x 1$ to $x 8$ in Figure 8 , while the output layer will be an EOR method. Each hidden layer is composed of basic processing elements called neurons. Each neuron is connected to the neurons of the adjacent layer with the connection weights between 0 and 1. The signals between the neurons are multiplied by the associated connection weights and added up together as Equation (1), and then used as the net input of the neuron as follows:

$$
N E T=\sum_{k=1}^{n} I_{k} W_{k}
$$

where:

NET is the net input of the neuron;

I is the input variable;

$W$ is the connection weight;

$k$ is the running index;

$\mathrm{n}$ is the number of input variables.

Each neuron applies an activation function to its net input to determine its output signal, and the signal is transmitted to the next neuron.

The activation function is added to an artificial neural network in order to help the network learn complex patterns in the data. Table 9 summarises the activation functions in terms of mathematical equations and their 1D plots. Among them, Sigmoid function is often used in ANN while ReLU is used in deep learning to avoid the vanishing gradient as reported by Giao and Kusan [21].

The connection weight function between the neurons is adjusted during the training processes. There are two ways of training, which are supervised and unsupervised training. For most typical neural networks, the connection weights are adjusted by the given input and corresponding output. This process is called supervised training. One of the widely used supervised networks is the feed-forward Back Propagation (BP) network which adjusts the connection weights during the back-propagation process. In this study, the BP network with the training algorithm of scaled conjugate gradient (SCG) - a new variation of the conjugate gradient method - is used.
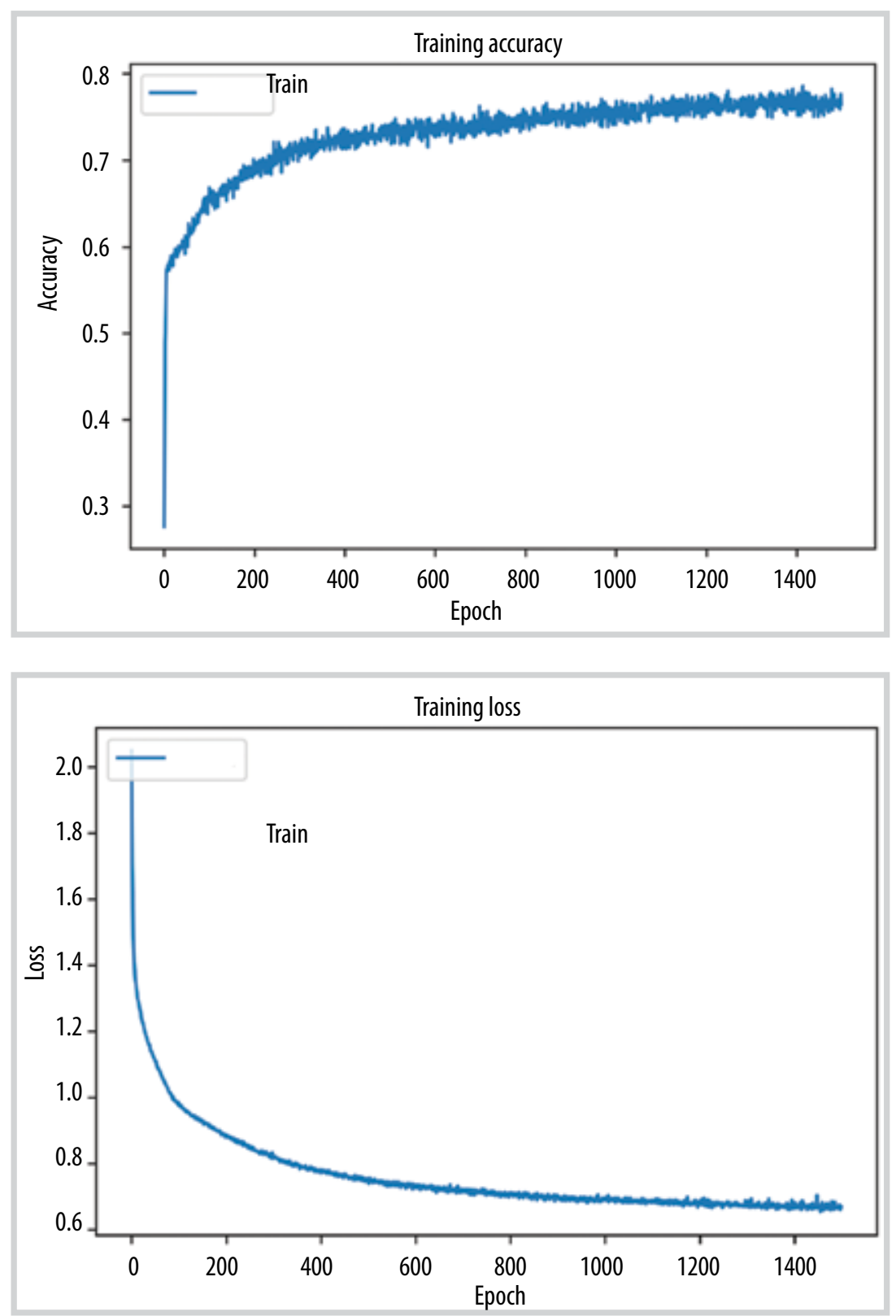

Figure 9. Training of result summaries. 
Table 10. Vietnam oil field properties as input for EOR screening model

\begin{tabular}{|c|c|c|c|c|c|c|c|c|c|}
\hline Field name & $\begin{array}{c}\text { Depth } \\
\text { (ft) }\end{array}$ & $\begin{array}{c}\text { Temp } \\
\left({ }^{\circ} \mathrm{C}\right)\end{array}$ & $\begin{array}{l}\text { Area } \\
\text { (arc) }\end{array}$ & $\begin{array}{c}\text { Porosity } \\
(\%)\end{array}$ & $\begin{array}{l}\text { Perm } \\
(\mathrm{mD})\end{array}$ & $\begin{array}{c}\text { API } \\
\text { Gravity }\end{array}$ & $\begin{array}{l}\text { Visc. } \\
\text { (cP) }\end{array}$ & $\begin{array}{c}\text { Oil saturation } \\
(\%)\end{array}$ & Reco-mmendation \\
\hline Field 1 & 10168 & 230 & 1200 & 16.5 & 50 & 33 & 0.9 & 80 & Polymer \\
\hline Field 2 & 10004 & 212 & 1500 & 15 & 30 & 32 & 1.1 & 60 & Polymer \\
\hline Field 3 & 9840 & 203 & 1800 & 18 & 160 & 29 & 4 & 50 & Polymer \\
\hline Field 4 & 9184 & 90 & 800 & 19 & 253 & 38.9 & 0.7 & 50 & Polymer \\
\hline Field 5 & 8856 & 194 & 700 & 23.2 & 185 & 37.9 & 0.7 & 50 & SP \\
\hline Field 6 & 5904 & 183.2 & 900 & 19 & 300 & 37 & 0.8 & 50 & $S P$ \\
\hline Field 7 & 6888 & 190 & 1000 & 26 & 1292 & 35.4 & 0.8 & 60 & Hydro carbon Miscible \\
\hline Field 8 & 10168 & 203 & 1020 & 18.8 & 293 & 37.9 & 0.8 & 60 & Polymer \\
\hline Field 9 & 10496 & 240 & 1300 & 12.04 & 31 & 38.7 & 0.7 & 40 & Polymer \\
\hline Field 10 & 10824 & 257 & 1200 & 10.25 & 20 & 38.7 & 0.7 & 40 & Polymer \\
\hline Field 11 & 10496 & 230 & 900 & 15 & 10 & 36 & 0.8 & 50 & Polymer \\
\hline Field 12 & 10496 & 203 & 900 & 22 & 247 & 37.7 & 0.8 & 50 & Polymer \\
\hline Field 13 & 10496 & 230 & 800 & 15 & 24.8 & 36 & 0.85 & 50 & Polymer \\
\hline
\end{tabular}

SCG allows the avoidance of the line search per training iteration of Levenberg-Marquardt approach to scale the step size.

With the collected EOR projects, the output of each project is the successful EOR method applied to a certain oil field. So each EOR method has to be categorised as a unit vector instead of naming them as a single number. For example, with 12 EOR methods mentioned above the categorised vector will be a 12-row element unit vector in which vector $\left(\begin{array}{lllll}1 & 0 & 0 & 0 & \ldots\end{array}\right)$ will be for method 1 ; vector $(0$ $100 \ldots 0)$ for method 2 and $(000 \ldots 1)$ will be for method 12 , respectively. Consequently, the output layer will be a matrix of $12 \times 1069$. Similarly, the input layer will be a matrix of $8 \times 1069$ data corresponding to 8 parameters. For training purposes, the data will be split into 2 sets: $80 \%$ of data for training and the rest $20 \%$ for validation.

These learning processes are implemented under the sequential model of Tensorflow package [22]. The sequential model is simple, allowing us to build a model layer by layer. In the network model, the layer type is "dense" which is the standard layer and can work for most of training cases. Compiling the model takes two parameters: optimiser and loss.

The optimiser controls the learning rate. In this study, Adam optimiser will be used since it is generally a good tool in many cases. The Adam optimiser adjusts the learning rate throughout training. The learning rate determines how fast the optimal weights for the model are calculated. A smaller learning rate may lead to more accurate weights (up to a certain point), but it will take longer to compute the weights.
For the loss function, the mean square error is calculated by taking the average squared difference between the predicted and the actual values as defined in the following equation:

$$
M S E=\frac{1}{N} \sum_{i=1}^{N}\left(f_{i}-y_{i}\right)^{2}
$$

where $\mathrm{N}$ is the number of data points, $f_{i}$ and $y_{i}$ are values returned by the training model and actual values of data point I, respectively. It is a popular loss function for regression problems. The closer to 0 it is, the better the model performed.

Figure 9 shows the result of training, including accuracy and training loss, respectively. The square correlation coefficient ( $r$-square) between the predicted output from the training model and the one from $20 \%$ validating data is 0.89 , which suggests that the training model is acceptable for further predicting. Once the training model was achieved, this model will be loaded with the input parameters (porosity, permeability, initial water saturation, viscosity, API (density), depth range, temperature, and area) from offshore oil fields of Vietnam (Table 10) to predict suitable EOR methods for these oil fields. The results are shown at the last column of Table 10. Here we can see that most of the recommended methods are polymer or surfactant polymer. Only one recommended method relates to gas miscible.

\section{Conclusions}

The following major conclusions were drawn from this study: 
This study could successfully collect and provide the most up-to-date EOR-project data sets as the first step in analysing EOR data and establishing screening criteria.

With the new dataset collected from EOR projects all over the world, an updated graphical method was proposed to find the range of parameters for conventional EOR screening. The statistical analyses conducted on these data sets gave an overall outlook of EOR methods. Additionally, a boxplot served as a very helpful tool for exploring and displaying the screening-criteria data set. This tool was used to update the conventional EOR screening method, giving more reasonable and applicable EOR method to each oil field. For example, regarding the polymer and surfactant injection method, the ranges of API, viscosity (cP), permeability (mD), porosity (\%), temperature $(\mathrm{F})$, depth $(\mathrm{ft})$ and initial oil saturation (\%) are 21 - 45, 0.32 - 288, 1 - 1218, 10 - 34, 10 - 34, 68 - 200, 650 9460 and $30-96$, respectively.

By applying the statistical analyses mentioned above for the input of the oil fields offshore Vietnam, it was found that the most recommended EOR method is chemical injection (polymer or polymer surfactant injection).

A deep learning network architecture was designed and tested in this study, consisting of an 8-input layer corresponding to eight reservoir properties, three 8-neuron hidden layers and an 1-output layer (the selected EOR method). Based on the initial DL prediction, the most recommended EOR method for mature oil fields in Vietnam is also polymer and polymer surfactant injection, with an exception of hydrocarbon miscible method being recommended for oil field No. 7 .

\section{Acknowledgement}

This research is supported by the national EOR project "Study on the EOR technique selection from laboratory to the field pilot test for mature oil fields in the Cuu Long basin", Ref. No. ĐTĐLCN.26/19. We would like to express our thanks to anonymous reviewer, Dr. Pham Huy Giao for valuable suggestions to improve the quality of the paper.

\section{References}

[1] Mark P. Walsh and Larry W Lake, A generalized approach to primary hydrocarbon recovery. Elsevier, 2003.

[2] Na Zhang, Mingzhen Wei, Jiayi Fan, Munqith Aldhaheria, Yandong Zhang and Baojun Bai, "Development of a hybrid scoring system for EOR screening by combining conventional screening guidelines and random forest algorithm", Fuel, Vol. 256, pp. 1 - 10, 2019. DOI: 10.1016/j. fuel.2019.115915.

[3] J.P. Brashear and V.A. Kuuskraa, "The potential and economics of enhanced oil recovery", Journal of Petroleum Technology, Vol. 30, No. 9, pp. 1231 - 1239, 1978. DOI: 10.2118/6350-PA.

[4] J.J. Taber, F.D. Martin and R.S. Seright, "EOR screening criteria revisited - Part 1: Introduction to screening criteria and enhanced recovery field projects", SPE Reservoir Engineering, Vol. 12, No. 3, pp. 189 - 198, 1997. DOI: 10.2118/35385-PA.

[5] J.J. Taber, F.D. Martin and R.S. Seright, "EOR screening criteria revisited - Part 2: Applications and impact of oil prices", SPE Reservoir Engineering, Vol. 12, No. 3, pp. 10 - 24, 1997. DOI: 10.2118/39234-PA.

[6] Ahmad Al Adasani and Baojun Bai, "Analysis of EOR projects and updated screening criteria", Journal of Petroleum Science and Engineering, Vol. 79, No. 1 - 2, pp. 10 - 24, 2011. DOI: 10.1016/j.petrol.2011.07.005.

[7] Vladimir Alvarado, Aaron Ranson, Karen Hernandez, Eduardo Manrique, Justo Matheus, Tamara Liscano and Natasha Prosperi, "Selection of EOR/IOR opportunities based on machine learning", European Petroleum Conference, 2002. DOI: 10.2118/78332-MS.

[8] Martina Siena, Alberto Guadagnini, Ernesto Della Rossa, Andrea Lamberti, Franco Masserano and Marco Rotondi, "A novel enhanced-oil-recovery screening approach based on Bayesian clustering and principal components analyses", SPE Reservoir Evaluation Engineering, Vol. 19, No. 3, pp. 382 - 390, 2016. DOI: 10.2118/174315-PA.

[9] D.R. Guerillot, "EOR screening with an expert system", Petroleum Computer Conference, San Jose, California, 1988. DOI: 10.2118/17791-MS.

[10] Ting-Horng Chung, Herbert B. Carroll and Rhonda Lidsey, "Application of fuzzy expert systems for EOR project risk analysis", SPE Annual Technical Conference and Exhibition, 1995. DOI: 10.2118/30741-MS.

[11] Mohamed Nageh, Mahmoud Abu El Ela, El Sayed El Tayeb and Helmy Sayyouh, "Application of using fuzzy logic as an artificial intellegce technique in screening criteria of the EOR technologies", SPE North Africa Technical Conference and Exhibition, 2015. DOI: 10.2118/175883-MS.

[12] Jong-Yong Lee and Jong-Se Lim, "Artificial neural network approach to selection of enhanced oil 
recovery method", Journal of the Korean Society of Mineral and Energy Resource Engineers, Vol. 45, No. 6, pp. 719 - 726, 2008.

[13] Geraldo Ramos and Lateef Akanji, "Technical screening of enhanced oil recovery methods - A case study Block C in offshore Angolan oilfields", First EAGE/ASGA Petroleum Exploration Workshop, 2017. DOI: 10.3997/22144609.201702357.

[14] Geraldo A.R. Ramos, Bruno Elias and Kyari Yates, "Screening reservoir candidates for enhanced oil recovery in Angolan offshore projects", Angolan Mineral, Oil and Gas Journal, Vol. 1, No. 1, pp. 6 - 10, 2020. DOI: 10.47444/ amogj.v1i1.3.

[15] G. Moritis, "CO injection gains momentum", Oil \& Gas Journal, Vol. 106, No. 15, pp. 46 - 57, 2006.

[16] G. Moritis, "California steam EOR produces less; other EOR continues", Oil \& Gas Journal, Vol. 100, pp. 43 77, 2002.

[17] G. Moritis, "EOR continues to unlock oil resources", Oil \& Gas Journal, Vol. 104, No. 15, pp. 45 - 65, 2004.

[18] G. Moritis, "EOR oil production up slightly", Oil \& Gas Journal, Vol. 96, No. 16, pp. 49 - 77, 1998.

[19] G. Moritis, "EOR weathers low oil prices", Oil \& Gas Journal, Vol. 98, No. 12, pp. 39 - 61, 2000.

[20] Ian Goodfellow, Yoshua Bengio and Aaron Courville, Deep learning. MIT Press, 2016.

[21] Pham Huy Giao and Kushan Sandunil, "Application of deep learning in predicting fracture porosity", Petrovietnam Journal, Vol. 10, pp. 14 - 22, 2017.

[22] Tensorflow, "Tensorflow", 2020. [Online]. Available: https://www.tensorflow.org/api_docs/python/ $\mathrm{tf} /$ keras/Sequential.

[23] Geraldo A.R. Ramos and Lateef Akanji, "Data analysis and Neuro-Fuzzy technique for EOR screening: Application for Angolian oil fields", Energies, Vol. 10, No. 7, pp. 10 - 33, 2017. DOI: 10.3390/en10070837. 